\title{
Correction to: Development of carbon dot-thiochrome-based sensing system for ratiometric fluorescence detection of D-penicillamine
}

\author{
Maolin $\mathrm{Wu}^{1,2} \cdot$ Nan Wang ${ }^{1} \cdot{\text { Zihan } \mathrm{Lin}^{2} \cdot \text { Xingguang Su}}^{1}$ \\ Received: 3 August 2021 / Accepted: 3 August 2021 / Published online: 20 August 2021 \\ (C) Springer-Verlag GmbH Germany, part of Springer Nature 2021
}

\section{Correction to: Analytical and Bioanalytical Chemistry} https://doi.org/10.1007/s00216-021-03552-9

Unfortunately, there was an error regarding the affiliations of the authors in this manuscript; please find the correct information below:

${ }^{1}$ Department of Analytical Chemistry, College of Chemistry, Jilin University, Changchun 130012, PR China

${ }^{2}$ College of Chemistry and Environmental Engineering, Changchun University of Science and Technology, Changchun 130022, PR China

The original article has been corrected.

Publisher's note Springer Nature remains neutral with regard to jurisdictional claims in published maps and institutional affiliations.

The online version of the original article can be found at https://doi.org/ $10.1007 / \mathrm{s} 00216-021-03552-9$

Xingguang $\mathrm{Su}$

suxg@jlu.edu.cn

1 Department of Analytical Chemistry, College of Chemistry, Jilin University, Changchun 130012, PR China

2 College of Chemistry and Environmental Engineering, Changchun University of Science and Technology, Changchun 130022, PR China 